\title{
Perceived Stress and Social Support Among Postgraduate Students: Implications for Well-Being and Engagement
}

\author{
Isaac Kosi \\ School of Business, University of Cape Coast, Ghana \\ E-mail: ikosi@ucc.edu.gh \\ https://doi.org/10.47963/jobed.2020.02
}

\begin{abstract}
Perceived stress and social support affect student well-being and engagement. Drawing on the Job Demand and Resource (JD-R) theory, this study examined perceived stress and social support on well-being (life satisfaction) and work engagement among postgraduate students in Ghana. Based on a cross-sectional survey and voluntary sampling technique, data were collected from 205 students, using a self-report questionnaire. The PLS-SEM ver3 was used to test the uniqueness of the constructs and to analyse the hypothesised path models. The findings suggest that perceived stress, social support and well-being play a crucial role in predicting student work engagement. Student well-being partially mediated the relationship between social support and engagement but not between perceived stress and engagement. In conclusion, this present study has shown that social support is critical for a student; hence, there is the need to improve support systems in the universities.
\end{abstract}

Keywords: Perceived stress, social support, well-being, life satisfaction, student engagement, Ghana 


\section{Introduction}

The significance of Higher education (HE) for individual and societal socio-economic development cannot be overemphasised. HE endows people with cultural competence and ability to work effectively with others from a diverse background (Zhao, Kuh \& Carini, 2005). HE provides them with much prospect and opportunities (Rickwood, Telford, O'Sullivan, Crisp, \& Magyar, 2016). Nevertheless, the quest for and pursuing HE is associated with stress (Bilgel \& Bayram, 2014; Kahu, \& Nelson, 2018). In Ghana, for example, a sample from a university student population indicated that 39.2 per cent (scored above the cut-off point of 10 on the CES-D scale) were depressed. That is, 31.1 per cent of the population had mild to moderate depressive symptoms, while 8.1 per cent indicated severe depressive symptoms (Asante \& Andoh-Arthur, 2015). More specifically, the stressors associated with pursuing postgraduate studies does not just affect students' academic performance, but also their mental and physical well-being (Zegeye, Mossie, Gebrie \& Markos, 2018). Indeed, the Job Demand-Resource model postulates that high 'work demand' leads to stress, which affects well-being and performance; availability of resources does not only improve stress but leads to engagement.

In the stress literature, the two forms of stress are eustress- a positive way that people are likely to experience when an external stimulus causes high arousal. In contrast, distress form tends to have adverse effects on physical and psychological wellbeing (Gerrig \& Zimbardo, 2010). From the distress perspectives, stress denotes "a situation in which a person feels tensed, restless, nervous or anxious, or is unable to sleep because his/her mind is troubled all the time" (Pyhältö, Toom, Stubb, \& Lonka, 2012, p. 4). Hence, a person's "inability to cope with a perceived (real or imaginary) threat to one's mental, physical, emotional, and spiritual well-being" (Seaward cited in Oswalt \& Riddock, 2007, p. 24). Studies have found a negative association between stress and students' academic performance (Mathew, Sudeep, Jain, \& Jain, 2017) due to psychological challenges including depression, anxiety and stress (Kugbey, Osei-Boadi, \& Atefoe, 2015).

Given the adverse effect of stress on individuals, there has been considerable trepidation about the mental health of university students globally (Stallman, 2010) due to the substantial vicissitudes and contests that prevail at the university level of education (Rickwood et al., 2016). Therefore, "providing students with access without support is not an opportunity" (Tinto \& Engstrom, 2008, p. 6). Thus, lack of resources (e.g., social support) make students become demotivated and feel disconnected from their work (Reeve, Shumaker, Yearwood, Crowell, \& Riley, 2013). Supporting students is critical as it influences their affiliation to the institutional culture and work ethics as well as enables them to graduate (Botha, 2017).

The literature on stress and social support and their consequential effect on postgraduate students' well-being and engagement indicate that not much scholarly work has been done, mainly in Ghana. However, the literature on individual well-being and engagement has been well-documented in many western countries, following the call by the positive psychology movement for the applied psychologist to focus on the optimal function of individuals (for a review, see Seligman \& Csikszentmihalyi, 2000). The past decades have not only witnessed increasing attention for the concept of well-being and engagement at the workplace (Schaufeli \& Taris, 2014), but also in the HE literature (Baron \& Corbin, 2012; Trowler, 2010). For instance, previous studies show that engagement is positively associated with student achievement (e.g., Valle et al., 2016). The importance of the concept of engagement cannot be interrogated (Trowler \& Trowler, 2010), since stakeholders in education regard student engagement as an essential requirement for student achievement (Baron \& Corbin, 2012). Also, the concept aids in dealing with "problems of student boredom, low achievement, and high dropout rates" (Wang \& Degol, 2014, p. 137). However, the mechanisms through which students become engaged in their studies have been sparsely examined and communicated, though student engagement is vital as engaged students are likely to complete their education (Kahu \& Nelson, 2018). Besides, orienting students on how to manage stress is essential for enhancing life satisfaction (well-being); therefore, it is academically imperative to determine the psychological conditions that relate to life satisfaction of students (Abolghasemia \& Varaniyab, 2010).

\section{Literature Review}

Several theoretical approaches and models or frameworks have been proposed to explain the causes and effect of stress on individual well-being and engagement (for a review, see Mark \& Smith, 2008). The JD-R framework is one of these, which Mark and Smith (2008) claim builds on the criticisms of the initial approaches. Although the JD-R model is a popular framework applied in the work setting research, very little is known in terms of its application in the school context. Thus, the school context presents students with study demands that cause stress and resources, which can affect their well-being and engagement (Salmela-Aro \& Upadyaya, 2014).

According to the Job Demand and Resource framework (JD-R; Bakker et al. 2007), every job setting includes demands and resources. The 'work demands' are those aspects of the 'job' that involves persistent physical and psychological efforts, which may cost the individual physically and psychologically. These refer to the adverse factors that sap energy; for example, workload and time pressure (Schaufeli, 2017). Whereas the resources are facets of the work- physical, psychological, social and organisational that abate the adverse effect of 'job' demands on the 
individual to function effectively (Schaufeli, 2017). Further, 'job' resources play buffering role to ameliorate the adverse effects of the job demands and stress on the individuals at the workplace and serve as a source motivation that, in turn, affect the psychological state of individuals (Schaufeli \& Taris, 2014). The framework is a heuristic model that signifies a dual process, which proposes that the high 'job' demands to lead to health erosion (e.g., psychological stress, burnout). At the same time, resource availability (e.g., support) enhances individual psychological state, thereby improving their well-being and task engagement.

\section{Social support}

Social support is significant in improving individual well-being and engagement. The notion of social support connotes "the function and quality of social relationships, such as perceived availability of help or support received" (Schwarze, Knoll \& Rieckmann, 2004, p. 2). This implies that social support can be subjective- the belief that one can obtain support when required, or objective-actual support received. Whichever, social support serves as a resource for coping with stress for the achievement of university obligations (Dupont, Galanda, \& Nils, 2015) as it influences the level of student psychological well-being (Kugbey et al., 2015). The significance of social support as an agent for promoting health and wellness has been recognised in the literature because of the buffering role against life stressors (Dollete, Steese, Phillips \& Matthews, 2004). Often, family, peers or friends are first the individuals who alert and express concerns and proffer help to a person when they notice something is wrong (Streeter \& Franklin, 1992). In this study, perceived social support refers to "one's overall impressions on whether the social network is supportive enough or not" (Sorias 1988b). In other words, "the perceived social support is the value of a person's self-estimation" (Sorias 1988a). Thus, social support is operationalised as having friends and other people, including lecturers/supervisors, peers and family, to go to in times of need or challenges to provide you with attention and positive self-image.

\section{Student engagement}

The concept of engagement is an essential phenomenon amongst institutions, including the HE sectors. However, there is a lack of consensus concerning the conceptualisation and definition of student engagement (for a review, see Ashwin \& Mcvitty, 2015). Trowler's (2010) analysis of the literature on student engagement indicated that many scholars (e.g., Fredricks, Blumenfeld, \& Paris, 2004; Glanville \& Wildhagen, 2007) conceptualised student engagement as a multifaceted construct that has three components - cognitive, emotional, and behavioural. The Australian Council of Educational Research (ACER) also describes student engagement as "students' involvement with activities and conditions likely to generate high-quality learning" (ACER, 2008, p. vi). In this current study, however, student engagement refers to a positive, fulfilling postgraduate studies experience operationalised as students' vigour, dedication and absorption (Schaufeli, Martinez, Pinto, Salanova, \& Bakker, 2002). Vigour denotes high levels of energy, vitality, and persistence, whereas dedication refers to a sense of meaning, enthusiasm, inspiration, pride, and challenge. On the other hand, absorption relates to being fully focused and passionately immersed in one's academic and research work and feeling excited about that work.

Several factors influence student engagement. For instance, Kuh;s (2013) conceptual model of student engagement shows that the antecedent of student engagement can be categorised as structural and psychosocial. The structural (distal) factors include university culture and curriculum; student background, peer relations and community influences, while the psychosocial (proximal) factors are teaching, motivation, personal skills, identity and self-efficacy. Although the conceptual framework does not capture all factors that may predict student engagement, student engagement is a situational phenomenon that develops from the interaction between individual attributes and contextual variables (Kuh, 2013). Thus, individual attributes, such as peer relations, and contextual factors, such as motivation from lecturers and supervisors' interact to influence student work engagement.

\section{Well-being}

Well-being is inherently an exciting concept, but difficult to explicitly define (White, 2008) as there are several varied terms used to depict the idea in the psychological literature (Diener, Pressman, Hunter \& Delgadillo-Chase, 2017). At best, the concept may be regarded as an abstraction used to represent the several well-evaluated facets of life (Travers \& Richardson 1993). Thus, the idea involves how individuals experience and evaluate aspects of their lives as positive (Tov, 2018). Therefore, well-being does not just represent the lack of illness or pathology but includes subjective and objective dimensions, which can be measured at the individual or societal levels (McAllister, 2005). Well-being is significant for an individual's growth and development and outcomes. For this individual-level study, such as subject well-being - how individuals evaluate or appraise their own lives (Diener et al., 2017) - is assessed, since it is a valid construct that can be reliably measured (Waldon, 2010).

Subjective well-being (SBW) is a 'broad concept that reflects individuals' emotional responses, domain satisfactions, and judgements of life satisfaction' (Diener et al., 1999: p. 277). SWB concept refers to "a person's cognitive and affective evaluations of his or her life" (Diener, Lucas, \& Oishi, 2002, p. 63). Conceptually, SWB 
comprises two distinctive components - an affective component, which relates to both the presence of positive affect and the absence of negative affect, and a cognitive component (for a review, see Diener, 1994, p. 106). The affective component is a hedonic evaluation driven by one's emotions and feeling. On the contrary, the cognitive component is an information-based judgement of one's life for which individuals judge the extent to which their present life compares to future 'ideal' experience. Research shows that positive SWB precedes varied positive personal, behavioural, psychological, and social outcomes (for a review, see Lyubomirsky et al., 2005).

In this study, SWB is measured as life satisfaction. Life satisfaction is one of the positive adjustment indicators, which can be affected by the stressful lives of college students. Accordingly, Heffner and Antaramian (2016) suggest that when predicting student success and school experiences, life satisfaction should be considered. Life satisfaction enables individuals to carry out long-term evaluations regardless of a particular time length (Eid \& Diener, 2004).

Based on the JD-R framework, the researcher avers that, like the work setting, the HE environment is also full of demands (e.g., assignments) and resources (e.g., support), which influence students well-being and engagement. Therefore, the influence of psychological stress and social support on postgraduate students' well-being and engagement may be adequately appreciated via the application of the JD-R model. As indicated by Sinclair, Christenson, Lehr, and Anderson (2003), "engagement is not an attribute of the student, but rather a state of being, which is highly influenced by contextual factors" (p. 31). Similarly, Veiga et al. (2012) claim that contextual factors are preferred issues to be explored to enhance engagement. In this research, the context includes the postgraduate students' perception of psychological stress and social support in the HE environment, which, from the JD-R framework perspectives, influences engagement and well-being. Therefore, this study draws on the JD-R framework to predict postgraduate students' engagement in Ghana.

Hence, this paper aimed at predicting postgraduate student work engagement by analysing mediation models. That is, determine whether 1). Perceived stress is negatively related to postgraduate student well-being and engagement. 2). Social support is positively associated with postgraduate student well-being and engagement 3 ). Well-being is positively associated with student engagement. 4). Well-being mediates the association between social support and student work engagement as well as perceived stress-students engagement models.

This current study is significant in two ways, thereby adding to existing literature. First, it examines the mechanism linking psychological stress and social support for postgraduate students' engagement. More importantly, building on the JD-R framework, the current study seeks to determine whether well-being serves as a mechanism for influencing graduate students' engagement. Student engagement is acknowledged as a 'good thing' by stakeholders (e.g., researchers and policymakers) in HE, because it is a resource for academic resilience that enables students to withstand and adapt to the stressors that stem from the demands and challenges of school work (Skinner \& Pitzer, 2012). Secondly, the present study informs practitioners (e.g., student support staff) and faculty of the need to devise interventions to improve stress and promote the well-being to enhance engagement among postgraduate students. This implies the need for setting up effective support services for postgraduate students, since this study seeks to show that social support buffers the effect of perceived stress on student engagement.

\section{Hypotheses development}

Psychological stress on student subjective wellbeing and engagement

Theoretically, the JD-R models suggest that stress affects well-being and engagement. As a psychological state, stress occurs when demands exhaust or surpass an individual's adaptive capabilities (Lazarus, 1966). Thus, stress hinders learning ability by impeding attention and memory; functions crucial for achievement (Fisher, 1994). However, when the conditions or situations are right, individuals, including students' innately engagement. In other words, when the learning conditions are suitable, students can direct their attention and energy on mastering a task and endure in times of challenges and difficulties (Wang \& Eccles, 2012a, 2012b). Nevertheless, the demands and challenging obligations on students (Offstein, Larson, McNeill, \& Mwale, 2004) lead to university students experiencing stress in their daily life (Dusselier, Dunn, Wang, Shelley, \& Whalen, 2005). For instance, postgraduate students experience a time of increased demands, expectations, and stress (Nelson, Dell'Oliver, Koch, \& Buckler, 2001) that expose students to psychological well-being problems (Roslan, Ahmad, Nabilla and Ghiami, 2017). Extant literature suggests that perceived stress negatively affects students' well-being (e.g., Lee, Kim \& Wachholtz, 2016; Sheu, Liu, \& Yue, 2017; Yang, Xia, Han \& Liang, 2018). More importantly, a recent meta-analysis study indicates that stress is negatively associated with quality of life (i.e., life satisfaction) among students as the stressors worsen conditions related to physical and mental health (Ribeiro et al., 2018). The negative impact of stress on well-being (i.e., life satisfaction) occurs when individuals perceive the situation as stressful and lack resources to deal with the precursors, such as workload and meeting deadlines (Roddenberry, 2007). In line with the JD-R theory, the research anticipated that the perception of stress would lead to strain among postgraduate students, hence, leading to low levels of well-being.

Besides, the goal and mission of postgraduate studies require students to be academically engaged. High-quality engagement ensures that students become academically competent and seek positive discourse (Skinner \& Pitzer, 
2012). Nonetheless, the engagement literature also indicates that stress adversely affects engagement. Past studies show that perceived stress negatively affects students' academic engagement (e.g., Durán, Extremera, Rey, Fernández-Berrocal, \& Montalbán, 2006; Gan, Yang, Zhou, \& Zhang, 2007; Pascoe, Hetrick \& Parker, 2019; Manikandan, \& Neethu, 2018; Raufelder et al., 2014). In parts, the negative association between stress and student engagement may stem from the pressure (e.g., much work, time limitations, tests) to succeed academically to graduate (Alginahi et al., 2009). Individuals who are confronted with high levels of strain are likely to engage in unhealthy behaviours (Hudd et al., 2000). These behaviours could include students not actively engaging in studies, which can lead to unsuccessful completion of the postgraduate programme. Accordingly, the JD-R theory suggests that high demands (stress) and a lack of resources lead to burnout, and for reduced 'work' engagement (Hakanen, Bakker \& Schaufeli, 2006). Based on the above theoretical and empirical evidence, it is hypothesised that:

Hla: Perceived stress will be negatively associated with postgraduate student well-being

H1b: Perceived stress will be negatively related to postgraduate student engagement.

Perceived social support on student subjective wellbeing and engagement

Theoretically, the JD-R theory postulates that resource (e.g., social support) availability is critical for individual wellbeing and functioning. Research shows that one of the significant predictors of SWB is the quality of social support (Lincoln, 2014; Siedlecki, Salthouse, Oishi, \& Jeswani, 2014). For instance, Siedlecki et al. (2014) found that life satisfaction was significantly predicted by perceived support. Similarly, another study observed social support (e.g., from friends) was significantly related to SBW (Brajša-Žganec, Lipovčan \& Hanzec, 2018). The reason for the positive relationship could be that those with a satisfying relationship can quickly receive support when needed. Similarly, individuals who have fulfilling relationships are happy most of the time and feel satisfied with their lives than those with a less satisfying relationship (Siedlecki et al., 2014). Therefore, the significant relationship between the quality of the social relationship and SWB could be explained by social support (ibid).

Besides, resources (e.g., social support) are inherently significant, because they also play intrinsic and extrinsic motivational roles by fostering growth, learning and development, and for attaining goals (Bakker \& Demerouti, 2008, p. 211). Indeed, enough resources lead to positive outcomes such as employee engagement (Law et al. 2011) and performance (Bakker \& Demerouti 2007). The Conservation of Resources (COR) theory (Hobfoll, 2001) suggests that individuals will seek to obtain, retain, and protect valuable resources, including, for example, social and personal resources. Thus, the acquisition and amassing of resources are essential to initiate and maintain people's behaviour (Salanova, Schaufeli, Xanthopoulou \& Bakker, 2010). Therefore, students are likely to remain actively engaged in school when they have positive learning experiences, such as supportive relationships from adults (e.g., supervisors/lecturers) and peers (Wang \& Eccles, 2013). One of the central elements that contribute to the successful completion of postgraduate studies is the supervisory role. As a resource, supervisors can foster self-efficacy belief among graduate students, which will, in turn, influence their level of engagement (Llorens, Schaufeli, Bakker, \& Salanova, 2007). In the workplace setting, studies have recognised that job resources, including social support, promote work engagement (Bakker \& Demerouti, 2008; Hakanen et al., 2006; Schaufeli \& Bakker, 2004; Schaufeli et al., 2009). Similarly, past studies indicate that social support influences student engagement (Bakker, Vergel, \& Kuntze, 2015; Fall \& Roberts, 2012; Klem \& Connell, 2009; Xerri, Radford, \& Shacklock, 2018; Zhao \& Kuh, 2004). Support structures, thus, "help the individual mobilise psychological resources and master psychological, emotional burdens; skills, and cognitive guidance to improve student handling of his/her situation (Caplan, 1974). In other words, students become engaged because they are emotionally connected to others (e.g., lecturer/supervisor, peers and family) as that enable them to become cognitively alert (Khan, 1990). Social support is a social capital that allows students to handle life stressors and effectively engages in their academic activities as they can draw on their social network in times of stressful moments. On the contrary, lack of social support has the propensity to cause psychological and physical disorders (Link \& Phelan, 1995). Therefore, drawing to the JD-R model, the researcher notes that high levels of resources, such as social support, do not only help prevent burnout, but foster engagement (Schaufeli, 2017). Based on the above theoretical and empirical evidence, it is hypothesised that:

H2a: Social support will be positively related to and predict student subjective well-being.

H2b: Social support will be positively associated with and predict student engagement

Student SWB and engagement

In recent times, there has been the need to identify those factors and conditions that influence "students' personal, prosocial and academic maturation and progress" (Neville, 2010, p. 2). Well-being is one of the critical factors for an individual's effective functioning. Students' well-being is vital for success at university since "it enables active learning, critical thought, optimal performance, social engagement and physical and mental health" (Stallman, Ohan \& Chiera, 2018, p. 365). However, the number of studies on students' well-being (i.e., life satisfaction) is small in comparison to that of adults, specifically within the school context (Huebner et al., 2011). Ensuring student well- 
being involves providing those conditions, which enable students to develop their abilities and flourish (Neville, 2010).

Previous studies show that well-being (i.e., life satisfaction) is positively associated with student engagement (e.g., Çaliskan, \& Mercangöz, 2013; Elmore, \& Huebner, 2010; Durón-Ramos, Vázquez, \& Lagares, 2018). The reason is that well-being encompasses "a framework of values and goals" (Neville, 2010, p.), which motivates students to be engaged in their studies. Indeed, motivation concerns energy and direction, hence, the motive for specific behaviou,r such as engagement, which defines power in action; the connection between person and activity" (Ainley, 2004, p. 2). More so, Heffner and Antaramian (2016) concluded in their study that life satisfaction provides "incremental validity over affective states in predicting student engagement and some aspects of academic achievement" (p. 1681). Also, drawing on the workplace literature on engagement, Bakker and Demerouti (2008) point out that the differences in performance among engaged and non-engaged workers are as a result of engaged workers' positive emotions, including happiness, joy and enthusiasm. Indeed, positive well-being can be related to positive health habits and frugal lifestyles (Demerouti \& Bakker, 2011), which allows individuals to engage in an activity. Base on the above argument, it is hypothesised that:

\section{H3: SWB will be positively related to student work engagement}

Perceived stress and social support on student work engagement: Mediating role of SWB

Perceived academic stress is a contextual factor that leads to psychological challenges, which affect students' wellbeing (Leung, Yeung, \& Wong, 2010). Previous studies indicate that perceived stress among students negatively influences their work engagement (e.g., Sheu et al., 2017; Yang et al., 2018). The experience of tension and discomfort among students leads to a deep sense of academic control in their studies due to a lowered sense of wellbeing, and lack of educational enjoyment and motivation (Zepke \& Leach, 2010).

Besides, social support is another significant contextual factor that plays a role in the perception of individuals' general subjective well-being (Tian, Zhao, \& Huebner, 2015). Knowledge of high well-being in school is positively associated with enjoying schoolwork and receiving necessary help, for instance, from teachers (Løhre, Lydersen, \& Vatten, 2010), which aids in student work engagement. Past studies indicate that social support positively affects student work engagement (e.g., Bakker, Vergel, \& Kuntze, 2015; Xerri, Radford, \& Shacklock, 2018). Thus, vigorous and dedicated students become actively absorbed in their studies, which makes them successful (Salanova et al. 2010) due to the support they receive. Nonetheless, the mechanisms through which individual students become engaged in their schoolwork have not been well articulated (Kahu \& Nelson, 2018), though the learning environment provides students with an overall SWB, which is influenced by the contextual factors (Tian et al., 2015). SWB is a vital indicator of individual wellbeing (Kahn \& Juster, 2002); hence a means for determining the effect of stress on a student's work outcomes (Diener \& Lucas, 2000).

SBW is denoted by the perception of students' life satisfaction in this study. The literature on life satisfaction suggests that the construct is not just a consequence of various psychological states (e.g., positive affect), but it is also a pointer of psychological states (e.g., work engagement) (Moksnes, Løhre, Lillefjell, Byrne \& Haugan, 2016). Many studies have focused on the mediating effect of well-being (e.g., life satisfaction) regarding stress and psychological outcomes. For example, several studies (e.g., Chang, Xing, Ho, \& Yip, 2019; McKnight et al., 2002; Suldo \& Huebner 2004b) have shown the mediating role of life satisfaction between stress and psychological outcomes. On the other hand, previous studies show that life satisfaction mediates the relationship between social support and psychological effects (e.g., Suldo \& Huebner 2004b) as students with a high level of life satisfaction tend to perceive great social support (Suldo \& Huebner, 2006).

Theoretically, the JD-R model postulates that contextual factors (e.g., social support) promote well-being by fulfilling students' psychological needs, which, in turn, lead to a psychological outcome (e.g., Student work engagement). Besides, the theory also proffers reasons that suggest that stress affects well-being (i.e., life satisfaction), which again, in turn, affect engagement. Thus, the JD-R model provides a balanced approach in elucidating negative as well as positive aspects of 'occupational' well-being (see Schaufeli \& Taris, 2014, for an overview). Therefore, drawing from the above empirical and theoretical propositions, the researcher argues that since contextual issues affect student engagement, there is a probability that student perception of stress will negatively affect their psychological health of students (i.e., well-being), which will, in turn, affect their academic engagement. On the contrary, social support will positively enhance postgraduate students' well-being, which will, in turn, influence their engagement in school. Based on the above theoretical and empirical evidence, it is hypothesised that: H4a: Student SWB will mediate the relationship between perceived stress and engagement.

$H 4 b$ : Student SWB will mediate the relationship between social support and engagement. 


\section{Methodology}

\section{Sample and data collection}

Based on the postpositivism paradigm, this study adopted the quantitative approach, which, according to Creswell (2009), is a method for analysing objective theories by investigating the association among variables. The variables can be usually measured on instruments, so that numerical data can be analysed using statistical procedures. A selfreported questionnaire was employed, since the researcher was interested in students perceived stress, social support, well-being and engagement. Data were collected within October and December 2019 from postgraduate students in two public universities in Ghana. Before the distribution of the questionnaires, the students were informed about the purpose of the study. Also, the students were informed that they could withdraw from taking part in the survey at any point in time, since participation is voluntary. Again, the students were also assured of the confidentiality of their responses. Based on the voluntary sampling technique, 205 completed responses (representing 68 per cent response rate) were returned to the author. Even though the voluntary sampling technique does not lead to generalisation of results, it does not require a sampling frame; involves minimal effort in distributing questionnaires to participants, since they regard participation in the study as worthwhile (International labour Organisation, 2009). The student sample comprised 52.7 per cent of master's degree, 40.5 per cent postgraduate diploma and 6.8 per cent PhD students. Of the 205 respondents, 56.1 per cent were males, and 42.9 per cent were females. Besides, a majority of the 205 respondents, representing 41.5 per cent, were between the ages of 25 and 30 . The researcher used previously validated scales to measure the constructs in the study's path model. SPSS ver21 was used to produce descriptive statistics, and to run exploratory factor analyses. PLS-SEM ver3 was used to test the structural (developed hypotheses) models.

\section{Measures}

Perceived stress: The Cohen, Kamarck and Mermelstein (1983) perceived stress scale was adopted to assess students' perceived stress. The nine-item scale was measured on a five-point Likert scale, from ' 0 ' $=$ Never to ' 4 ' $=$ Very Often. Example of the items include, 'How often during the last month did you feel nervous and stressed'? Social support: This study measured social support using a 17-item scale adapted from Zimet, Dahlem, Zimet, and Farley (1988) and Malecki and Demaray (2002). Respondents were asked to specify their agreement with statements related to support received from lecturers, peers and family on a seven-point Likert scale, from ' 1 ' $=$ strongly disagree to ' 7 ' = strongly agree. Sample items included, 'My lecturer/supervisor is willing to help me when I need a special favour'. 'I have peers with whom I can share my joys and sorrows' and Life satisfaction: This study adopted the five-item Satisfaction With Life Scale developed by Diener, Emmnos, Larsen, and Griffin (SWLS;1985) to measure postgraduate students' subjective well-being. Respondents were requested to reflect on how they generally feel about their life now on a five-point Likert scale, from ' 1 ' $=$ strongly disagree to ' 5 ' $=$ strongly agree. Sample items included 'In most ways, my life is close to my ideal.' Student work engagement: The study used Schaufeli and Bakker (2003) Utrecht Work Engagement Scale, Student Version (UWES-S) to measure postgraduate students' work engagement. Respondents were asked to reflect on how they felt at school by indicating their agreement with statements on a seven-point Likert scale, from ' 0 ' $=$ Never to ' 6 '= Always. The 17 -item scale consists of sub-scales items measuring vigour (e.g., When I study, I feel that I am bursting with energy), dedication (e.g., I am enthusiastic about my studies), and absorption (e.g., time flies when I am studying).

\section{Data analysis}

Prior to the quantitative analyses, the dataset was examined for accuracy of the data entry and missing values; cases with too few or no responses in the variables of interest were removed from the dataset. In order to examine the hypotheses, this study followed Hair, Risher, Sarstedt and Ringle's (2019) two-step process (an assessment of the measurement model and the structural model) for PLS-SEM analysis. The choice of PLS-SEM was based on the study objective of estimating "the model's indicator variables and the structural path without imposing distributional assumption on the study data" (Hair et al., 2019, p. 2) as well as accounting for the total variance and uses the total variance to estimate parameters unlike the Covariance Based Structural Equation Modelling (CB-SEM) (Hair et al., 2017b).

\section{Measurement model assessment}

The first step in a measurement model assessment was the examination of the indicator loadings. Following this was the assessment of internal consistency reliability using composite reliability (CR). The composite reliability is a more appropriate measure of internal consistency than the Cronbach's alpha (CA,) since the CA's value is susceptible to the number of items in a scale (Rossiter, 2002). Next, the convergent validity of each construct was assessed, using the Average Variance Extracted (AVE). The final step was the discriminant validity, using the Fornell Larcker criterion and the Heterotrait-Monotrait Ratio (HTMT). 
Table 1: Outer loadings

\begin{tabular}{lllll}
\hline Items & Loadings & CA & CR & AVE \\
\hline LIFE SATISFACTION & & 0.815 & 0.878 & 0.644 \\
LS2 & 0.834 & & & \\
LS3 & 0.845 & & & \\
LS4 & 0.804 & & & \\
LS5 & 0.721 & & & \\
PERCEIVED STRESS & & 0.643 & 0.804 & 0.579 \\
PSS4 & 0.711 & & & \\
PSS5 & 0.772 & & & \\
PSS8 & 0.796 & & & \\
SOCIAL SUPPORT & & 0.894 & 0.913 & \\
SS10 & 0.703 & & & \\
SS12 & 0.743 & & & \\
SS14 & 0.606 & & & \\
SS17 & 0.756 & & & \\
SS2 & 0.705 & & & \\
SS4 & 0.767 & & & \\
SS5 & 0.737 & & & \\
SS6 & 0.677 & & & \\
SS7 & 0.763 & & & \\
SS9 & 0.693 & & & \\
STUDENT WORK ENGAGEMENT & & & \\
SED2 & 0.610 & \\
SED3 & 0.759 & & \\
SEV1 & 0.838 & \\
SEV2 & 0.765 & & & \\
SEV4 & 0.760 & & & \\
\hline
\end{tabular}

Table 1 shows that almost all indicators loaded above the threshold of 0.7 . The few items that loaded below 0.7 were not deleted because they did not affect the reliability of the constructs. A measurement model is appropriate when its indicators loaded above 0.70 on the latent variables or loaded "between 0.4 and 0.7 " in situations where removing the indicators does not lead to an increase in the reliability of the model (Hair et al., 2014). The results in Table 1 indicates that all latent variables in this study are reliable, as they all ranged between 0.838 and 0.913 , loading well above the 0.7 thresholds by (Bagozzi \& Yi, 1988). The Average Variance Extracted (AVE) was used to measure the convergent validity in the model. The results from Table 1 shows that the AVE values range between 0.510 and 0.644, which according to Hair et al. (2019), AVE value of 0.50 or higher indicates that the construct explains 50 per cent or more of the variance of the items that make up the construct - implying that the constructs in the model have convergent validity. As part of the measurement model assessment, the Fornell-Lacker criterion and the HeterotraitMonotrait Ratio (HTMT) were employed to establish discriminant validity.

Table 2: Fornell-Larcker Criterion

\begin{tabular}{|c|c|c|c|c|c|}
\hline \multicolumn{2}{|c|}{ Constructs } & 1 & 2 & 3 & 4 \\
\hline 1. & Life Satisfaction & 0.803 & & & \\
\hline 2. & Perceived Stress & -0.324 & 0.761 & & \\
\hline 3. & Social Support & 0.553 & -0.450 & 0.716 & \\
\hline 4. & Student Work Engagement & 0.414 & -0.495 & 0.496 & 0.714 \\
\hline
\end{tabular}

Discriminant validity shows how a construct is empirically distinct from other constructs in the model (Hair et al., 2019). To establish discriminant validity, the square root of the AVE of each construct must be higher than its highest correlations with other constructs in the model (Fornell \& Larcker, 1981). The results show that the AVE values of each construct (latent variable) are higher than the value of the correlation between the constructs (see Table 2), thereby suggesting the requirement of discriminant validity is established. The Fornell-Lacker criterion 
does not perform well when indicator loadings are close (Henseler et al.,2015). Given the closeness of the loadings of items in the model, the HTMT was also adopted to ensure the robustness of the model.

Table 3: Heterotrait-Monotrait Ratio (HTMT)

\section{1} 2 3

4

\begin{tabular}{lllll}
\hline 1. & Life Satisfaction & & \\
2. & Perceived Stress & 0.434 & \\
& & & \\
& & {$[0.027,0.297]$} & & \\
3. & Social Support & 0.639 & 0.567 & \\
& & {$[0.412,0.610]$} & {$[-0.555,-0.354]$} & \\
4. & Student Work Engagement & 0.506 & 0.692 & 0.592 \\
& & {$[0.027,0.297]$} & {$[-0.463,-0.198]$} & {$[0.114,0.403]$} \\
\hline
\end{tabular}

Based on a more conservative threshold, a latent construct has discriminant validity when its HTMT ratio is below 0.850 (Henseler et al., 2015) and the confidence interval, indicating the range into which the actual HTMT population value will fall must not contain the value 1 (Hair et al., 2017). The results in Table 3 shows that all HTMT values are well below the threshold of 0.850 . Also, neither the lower nor the upper confidence interval of any construct includes the value 1, indicating that discriminant validity has been established for this study. Based on the measurement model indicators, the structural model was examined.

\section{Results and Discussion}

\section{Structural Model Assessment}

The standard criteria for structural model assessment in PLS-SEM include Coefficient of determination $\left(\mathrm{R}^{2}\right)$, the blindfolding-based cross-validated redundancy measure $\left(\mathrm{Q}^{2}\right)$, the effect size $\left(\mathrm{f}^{2}\right)$, as well as the statistical significance and relevance of the path coefficients (Hair et al., 2019). The model indicating the various paths is shown in Figure 1. The assessment of the structural model began with an assessment of the lateral collinearity among the constructs. Collinearity among constructs needs to be measured to ensure that it does not bias the regression results (Hair et al., 2019). According to Becker et al. (2015), variance inflation factor (VIF) value of 5 and above are indicative of pathological collinearity problems and values greater than 3.3 may also indicate that the model may be contaminated by common method bias (Kock, 2013). The results in Table 4 suggest that VIF in all cases is less than 2, indicating that lateral multicollinearity is not a problem in this study (Hair et al., 2014).

Table 4: Collinearity statistics (VIF)

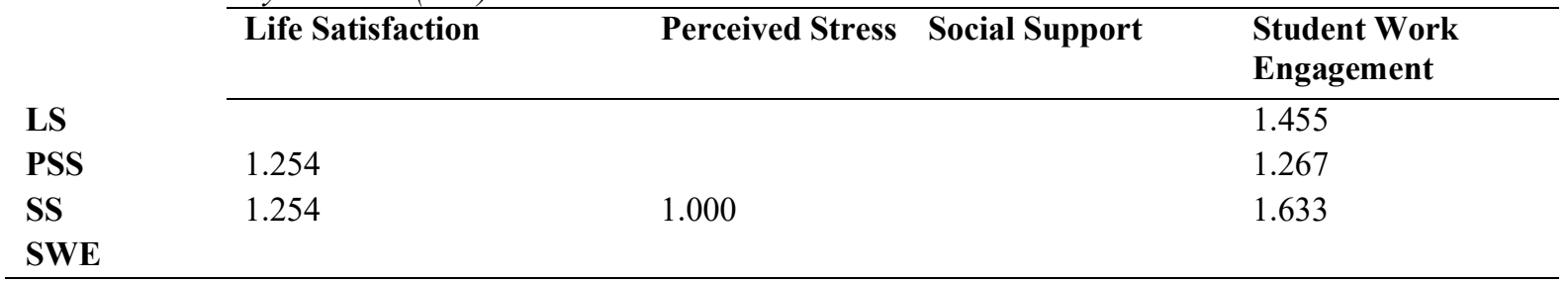

The assessment of the structural paths (hypotheses) and the explanatory power of the model is presented in Table 5 with reference to Figure 1 . The assessment began by evaluating the variance explained by the endogenous variables in the model, using the $\mathrm{R}^{2}$, which is a measure of a model's explanatory power (Shumeli \& Koppius, 2011). 


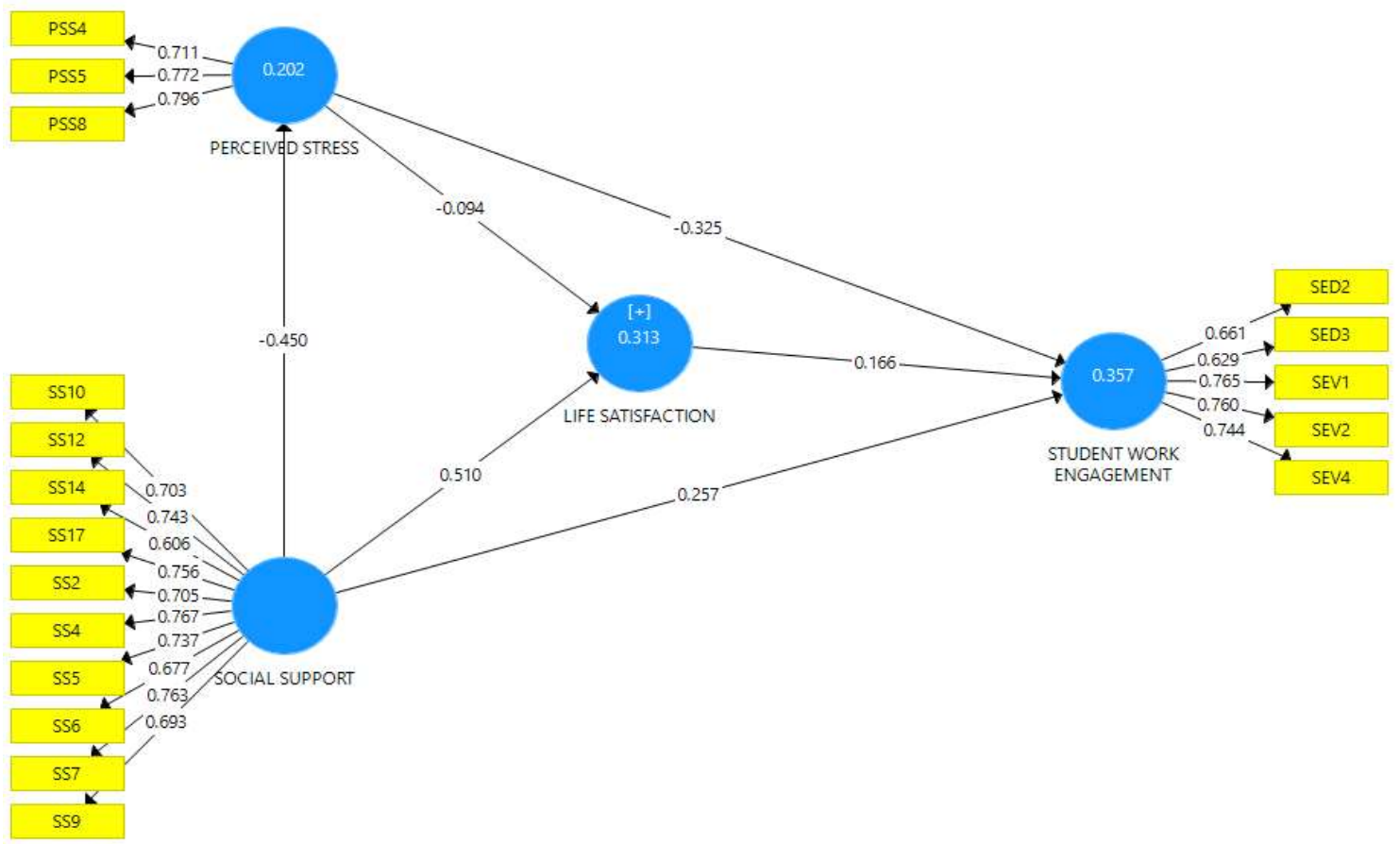

Figure 1: Structural Path Model

The $\mathrm{R}^{2}$ values in the structural model (Figure 1) shows that Student Work Engagement (SWE) has an $\mathrm{R}^{2}$ value of 0.357, indicating that the entire model accounts for 35.7 per cent of the variance in student work engagement. Hair et al. (2019) indicate that $\mathrm{R}^{2}$ values of almost 50 per cent show moderate explanatory power. Figure 1 also shows that Life Satisfaction (LS) has an $\mathrm{R}^{2}$ value of 0.313, implying that Perceived Stress and Social Support account for 31.3 per cent of the variance in students Life Satisfaction. The $\mathrm{R}^{2}$ value of 0.202 for Perceived Stress indicates that social support accounts for 20.3 per cent of the variance in perceived stress. Based on the criteria proposed by Hair et al. (2019), this indicates substantial predictive power of the model. Besides evaluating the $\mathrm{R}^{2}$ of the model, the contribution of each predictor to an endogenous construct's $\mathrm{R}^{2}$ was assessed, using the effect size $\left(f^{2}\right)$. The $f^{2}$ effect sizes indicate a predictor's relevance in explaining a dependent construct in a model (Hair et al., 2019). Values greater than $0.02,0.15$ and 0.35 indicate small, moderate, and large $f$ effect sizes, respectively (Cohen, 1988). The results from Table 5 show that Social support (SS) has the largest effect on life satisfaction (LS) $\left(\mathrm{f}^{2}=0.302\right)$ and also has a moderate effect on perceived stress $\left(\mathrm{f}^{2}=0.254\right)$ while having a small effect on student work engagement $\left(\left(f^{2}=0.302\right)\right.$. The results also show that Perceived stress had a moderate effect size on student work engagement $\left(\mathrm{f}^{2}=0.130\right)$ and a small effect on life satisfaction $\left(\mathrm{f}^{2}=0.010\right)$. The results also show that life satisfaction had a small effect on student 'work engagement' $\left(\mathrm{f}^{2}=0.030\right)$.

Table 5: Structural model results (Direct effect)

\begin{tabular}{llllllll}
\hline Structural Path & $\begin{array}{l}\text { Path } \\
\text { Coefficient }\end{array}$ & $\begin{array}{l}\mathrm{T} \text { Statistics } \\
(|\mathrm{O} / \mathrm{STDEV}|)\end{array}$ & $P$-Value & $\mathrm{R}^{2}$ & $\mathrm{f}^{2}$ & $\mathrm{Q}^{2}$ & Conclusion \\
\hline LS - $\mathbf{S W E}$ & 0.166 & 2.407 & 0.016 & 0.357 & 0.030 & 0.170 & Supported \\
PSS -> LS & -0.094 & 1.427 & 0.154 & 0.313 & 0.010 & 0.192 & Not Supported \\
PSS -> SWE & -0.325 & 4.842 & 0.000 & 0.357 & 0.130 & 0.170 & Supported \\
SS -> LS & 0.510 & 10.277 & 0.000 & 0.313 & 0.302 & 0.192 & Supported \\
SS -> PSS & -0.450 & 8.817 & 0.000 & 0.202 & 0.254 & 0.108 & Supported \\
SS -> SWE & 0.257 & 3.466 & 0.001 & 0.357 & 0.063 & 0.170 & Supported \\
\hline
\end{tabular}


In addition to explanatory power, the predictive accuracy was assessed, using the $\mathrm{Q}^{2}$ (Geisser, 1974; Stone, 1974). As a guideline, Hair et al. (2019) propose that $\mathrm{Q}^{2}$ values should be larger than zero for a specific endogenous construct to indicate the predictive accuracy of the structural model for the construct. Specifically, $\mathrm{Q}^{2}$ values higher than 0 , 0.25 , and 0.5 show small, medium, and high predictive relevance. The results show $\mathrm{Q}^{2}$ values of 0.170 for student work engagement, 0.192 for life satisfaction, and 0.108 for perceived stress. The model met the general requirement that $\mathrm{Q}^{2}$ should be greater than 0 , also, except all predictors in the model had close to a medium predictive relevance on the endogenous variables.

The paper examined six direct paths indicating the various hypothesis (Figure 1). The results of the structural model indicate that perceived stress is not significant in predicting a student's life satisfaction $(\beta=-0.094 ; p>0.05)$, even though a negative relationship exists between the two variables; therefore, H1a is rejected. Additionally, the results also support a significant negative relationship between perceived stress and student work engagement $(\beta=$ $0.325, \mathrm{p}<0.05), \mathrm{H} 1 \mathrm{~b}$ is, therefore, supported, that perceived stress is negatively related to postgraduate students' work engagement. Again, the results establish a positive relationship between social support and life satisfaction ( $\beta$ $=0.510, \mathrm{p}<0.05$ ); as a result, $\mathrm{H} 2 \mathrm{a}$ is supported. Social support was found to be positively related to postgraduate students' work engagement $(\beta=0.257, p<0.05)$, indicating support for hypothesis $2 b$. The results also indicate that life satisfaction contributes significantly to explaining and predicting postgraduate students' work engagement ( $\beta=$ $0.166 ; \mathrm{p}<0.05$ ); therefore, $\mathrm{H} 3$ is supported. Social support is, however, found to be negatively related to the level of perceived stress among postgraduate students $(\beta=-0.450, p<0.05$ : Table 5: Figure 1$)$, providing support for H5. The results show that all hypothesised direct relationships were statistically significant, except for perceived stress and life satisfaction. The mediation effect of life satisfaction was also analysed, results shown in Table 6.

Table 6: Mediation Analysis

\begin{tabular}{llllll}
\hline PATH & Path Coefficient & $\begin{array}{l}\text { Standard } \\
\text { Deviation } \\
(\text { STDEV })\end{array}$ & $\begin{array}{l}\text { T } \\
(\mid \mathbf{O} / \text { STDEV } \mid)\end{array}$ & Conclusion \\
\hline PSS -> LS -> SWE & -0.016 & 0.013 & 1.160 & 0.246 & Not Supported \\
SS -> LS -> SWE & 0.085 & 0.036 & 2.330 & 0.020 & Supported
\end{tabular}

This study adopted the procedure developed by Nitzl, Roldán, and Cepeda (2016) to test mediation effects in PLS-SEM in this study. Nitzl et al. (2016) propose that a significant indirect effect is the only prerequisite for establishing a mediation effect, unlike a two-step analysis, as proposed by Baron and Kenny (1986). The significance of the direct effect determines the type of effect and or mediation. There are two different types of mediation, full and partial mediation (Hair et al., 2017). Partial mediation occurs when both the direct and indirect effects are statistically significant; it can be subdivided into complementary and competitive partial mediation. A full mediation occurs when a direct effect is not significant while an indirect is significant. Thus, a situation where the relationship is only possible through the mediating variable (Carrión, Nitzl \& Roldán, 2017). A complementary partial mediation occurs when both the direct and indirect effect point in the same direction (+ or -) (Baron \& Kenny, 1986), while in a competitive mediation, they point to opposite directions (Carrión et al., 2017). Hypothesis 4a predicted that Student life satisfaction would mediate the relationship between perceived stress and postgraduate student engagement. The results from Table 6 show that the indirect effect (PSS - $>$ LS - $>$ SWE) is not significant $(\beta=-0.016, p>0.05)$; therefore, $\mathrm{H} 4 \mathrm{a}$ is not supported. Finally, hypothesis $4 \mathrm{~b}$ predicted that student life satisfaction would mediate the relationship between social support and postgraduate student engagement. Following the procedure defined by Nitzl et al. (2016), the indirect effect (SS -> LS -> SWE) was found to be statistically significant $(\beta=0.085, p<0.05)$, indicating that $\mathrm{H} 4 \mathrm{~b}$ is supported. Given that the direct effect is significant, the nature of the mediation effect of life satisfaction on the relationship between social support and postgraduate student work engagement is a complimentary mediation (Zhao, Lynch Jr, \& Chen, 2010).

\section{Discussion}

Drawing on the JD-R theory as the theoretical lens, this study examined the effect of perceived stress and social support (school contextual factors) on students' well-being and engagement. Besides, the study investigated wellbeing as the underlying mechanism by testing mediation models. This current study has primarily provided empirical evidence, showing the effects of stress and social support on student well-being and engagement in the Ghanaian setting. First, consistent with the JD-R theory and previous studies (e.g., Hetrick \& Parker, 2019; Manikandan, \& Neethu, 2018; Raufelder et al., 2014), a significant negative relationship was found between perceived stress and 
student 'work engagement,' suggesting that perceived stress is a challenging phenomenon, which affects postgraduate student desire to expend energy on academic activities.

However, inconsistent with most studies (e.g., Lee et al., 2016; Sheu et al., 2017; Yang et al., 2018) and theoretical assumptions underpinning this study, a surprising result was found as perceived stress was not a significant predictor of student life satisfaction, though negative relationship exists between the two variables. Perhaps, the data suggest that students may perceive less stress due to the availability of perceived and actual social support. Thus, students perceive the school context factors are positively challenging and controllable (Lee et al., 2016) as social support is significantly and negatively related to perceived stress in this study. Second, the results also show that social support is positively associated with and significantly predicts postgraduate student well-being and work engagement. The result is akin to previous studies (e.g., Brajša-Žganec et al., 2018; Siedlecki et al., 2014) that examined the relationship between social support and students' well-being. More so, the result is also consistent with past studies (Bakker et al., 2015; Fall \& Roberts, 2012; Klem \& Connell, 2009; Xerri et al. 2018; Zhao \& Kuh, 2004), which found that social support is significantly positively related to student work engagement. Like social support results in positive outcomes influencing students, this study echoes the significance of the school environment social support in promoting positive learning behaviours. The findings lend support to the JD-R theory and stress literature, depicting that social support is a vital resource mitigating the negative effect of stress, and a source of motivation.

Fourth, the study found that postgraduate student life satisfaction positively related and significantly predicts their schoolwork engagement. The result is akin to previous studies, such as Çaliskan and Mercangöz (2013), Elmore and Huebner (2010) and Durón-Ramos et al. (2018), that student well-being is essential for their engagement. Hence, prompting the need to promote positive factors in students to enhance their academic performance and personal growth (Ramos et al., 2018). Fifth, in response to the need for more investigations on mechanisms through which individual students become engaged in their schoolwork, this study examined the mediating effect of life satisfaction and found that student life satisfaction is a significant factor in explaining how students become engaged in schoolwork. Theoretically, social support aids a student to mobilise the needed psychological resources to manage the adverse effects of school demands. Hence, life satisfaction as a mechanism for comprehending the relationship between social support and student 'work' engagement is an essential resource for promoting a positive learning attitude and behaviours among postgraduate students. On the contrary, life satisfaction was not a significant mediator between perceived stress and student work engagement. This result contrasts the JD-R theoretical assumption and empirical evidence that suggest that well-being (i.e., life satisfaction) mediates stress-psychological outcome models.

\section{Conclusion}

In sum, this present study has provided support for the theoretical assumption of the JD-R model. Again, consistent with past research results, this study affirmed that perceived stress, social support and life satisfaction are' vital antecedents of student 'work engagement.' Thus, like most past studies around the world, perceived stress, social support and life satisfaction are crucial factors for student work engagement in the Ghanaian context. This implies that HE institutions should not only provide easily accessible academic services, but personal and social support services to improve postgraduate student retention and timely completion.

Like most cross-sectional survey studies, data was limited to postgraduate students in two public universities in Ghana and data collection was cross-sectional; hence, limiting the ability to assess the causal relationship. Further, the sample size is comparatively smaller, but the results were not adversely affected. It is recommended that future research can focus on longitudinal design and use a sampling technique that allows for generalisation. More so, there is a need to focus on the application of Self-Determination Theory in the stress-student engagement model, which assumes that a high level of self-determination buffers the harmful effects of stressors. 


\section{References}

Abolghasemi, A., \& Varaniyab, S. T. (2010). Resilience and perceived stress: predictors of life satisfaction in the students of success and failure. Procedia-Social and Behavioral Sciences, 5, 748-752.

Ainley, M. (2012). Students' interest and engagement in classroom activities. In Handbook of research on student engagement (pp. 283-302). Springer, Boston, MA.

Alginahi, Y. M., Ahmed, M., Tayad, O., Siddiqi, A. A., Sharif, L., Alharby, A. and Nour, R. (2009). ICT students, stress and coping strategies: English perspective a case study of Midsize Middle Eastern University. TRIM, $5(2), 111-127$.

Asante, K. O., \& Andoh-Arthur, J. (2015). Prevalence and determinants of depressive symptoms among university students in Ghana. Journal of Affective Disorders, 171, 161-166.

Ashwin, P., \& McVitty, D. (2015). "The Meanings of Student Engagement: Implications for Policies and Practices." In The European Higher Education Area, edited by A. Curaj, L. Matei, R. Pricopie, J. Salmi, and P. Scott, 343-359. London: Springer

Australian Council for Educational Research (2008). Attracting, engaging and retaining: New conversations about learning. Australasian student engagement report. Camberwell, Victoria: Author

Bakker, AB \& Demerouti, E. (2007), "The job demands-resources model: state-of-the-art", Journal of Managerial Psychology, Vol. 22, pp. 309-28.

Bakker, A.B. \& Demerouti, E. (2008), “Towards a model of work engagement”, Career Development International, Vol. 13, pp. 209-23.

Bakker, A. B., Vergel, A. I. S. \& Kuntze, J. (2015). Student engagement and performance: A weekly diary study on the role of openness. Motivation and Emotion, 39(1), 49-62.

Baron, P., \& Corbin, L. (2012). Student engagement: Rhetoric and reality. Higher Education Research \& Development, 31(6), 759-772.

Bilgel, N., \& Bayram, N. (2014). The epidemiology of depression, anxiety, stress and anger in Turkish high school students. Journal of Education, Society and Behavioural Science, 1153-1170.

Botha, R. N. (2017). Postgraduate Student Throughput at the University of Ghana. European Scientific Journal, ESJ, 12(10), 342-355.

Brown, K. W., \& Ryan, R. M. (2003). The benefits of being present: mindfulness and its role in psychological wellbeing. Journal of Personality and Social Psychology, 84(4), 822-848

Çaliskan, B. Ö. Ö. \& Mercangöz, B. A. (2013). Satisfaction and academic engagement among undergraduate students: A case study in Istanbul University. International Journal of Research in Business and Social Science, 2(4), 84.

Chang, Q., Xing, J., Ho, R. T., \& Yip, P. S. (2019). Cyberbullying and suicide ideation among Hong Kong adolescents: The mitigating effects of life satisfaction with family, classmates and academic results. Psychiatry Research, 274, 269-273.

Chao, R. C. L. (2012). Managing perceived stress among college students: The roles of social support and dysfunctional coping. Journal of College Counselling, 15(1), 5-21.

Cohen, J. (1998). Statistical Power Analysis for Behavioral Sciences, $2^{\text {nd }}$ edition. Lawrence Erlbaum Associates

Creswell, J. W. (2009). Research design: Qualitative and mixed methods approaches. London and Thousand Oaks: Sage Publications.

Demerouti, E., \& Bakker, A. B. (2011). The job demands-resources model: Challenges for future research. $S A$ Journal of Industrial Psychology, 37(2), 01-09.

Diener, E., Emmons, R. A., Larsen, R. J, \& Griffin, S. (1985). The Satisfaction with Life Scale. Journal of Personality Assessment 49(1):71-75.

Diener, E., Pressman, S. D., Hunter, J., \& Delgadillo-Chase, D. (2017). If, why, and when subjective well-being influences health and future needed research. Applied Psychology: Health and Well-Being, 9(2), 133-167.

Diener, E., Suh, E. M., Lucas, R. E., \& Smith, H. L. (1999). Subjective well-being: Three decades of progress. Psychological Bulletin, 125(2), 276.

Diener, E., Lucas, R. E., \& Oishi, S. (2002). Subjective well-being: The science of happiness and life satisfaction. Handbook of positive psychology, 2, 63-73.

Diener, E. (1994). Assessing subjective well-being: Progress and opportunities. Social Indicators Research, 31, 103157

Dolan, P. (2008). Social support, social justice, and social capital: A tentative theoretical triad for community development. Journal of Community Development, 39:1, 112119 DOI: 10.1080/15575330809489745

Dollette, M., Steese, S., Phillips, W \& Matthews, G. (2004). Understanding girls' circle as an intervention on perceived social support, body image, self-efficacy, locus of control and self-esteem. The Journal of Psychology, 90 (2), $204-215$. 
Dupont, S., Galand, B., \& Nils, F. (2015). The impact of different sources of social support on academic performance: Intervening factors and mediated pathways in the case of master's thesis. European Review of Applied Psychology, 65(5), 227-237.

Durán, M. A., Extremera, N., Rey, L., Fernández-Berrocal, P., \& Montalbán, F. M. (2006). Predicting academic burnout and engagement in educational settings: Assessing the incremental validity of perceived emotional intelligence beyond perceived stress and general self-efficacy. Psicothema, 18.

Dusselier, L., Dunn, B., Wang, Y., Shelley iI, M. C., \& Whalen, D. F. (2005). Personal, health, academic, and environmental predictors of stress for residence hall students. Journal of American college health, 54(1), $15-24$.

Eid, M., \& Diener, E. (2004). Global judgments of subjective well-being: Situational variability and long-term stability. Social indicators research, 65(3), 245-277.

Elmore, G. M., \& Huebner, E. S. (2010). Adolescents' satisfaction with school experiences: Relationships with demographics, attachment relationships, and school engagement behaviour. Psychology in the Schools, 47(6), 525-537.

Fall, A. M., \& Roberts, G. (2012). High school dropouts: Interactions between social context, self-perceptions, school engagement, and student dropout. Journal of adolescence, 35(4), 787-798.

Fisher, S. (1994). Stress in Academic Life: The Mental Assembly Line. Buckingham: Open University Press

Fredricks, J. A., Blumenfeld, P. C., \& Paris, A. H. (2004). School engagement: Potential of the concept, state of the evidence. Review of Educational Research, 74(1), 59-109.

Fornell, C. G. \& Larcker, D. F. (1981) Evaluating Structural Equation Models with Unobservable Variables and Measurement Error. Journal of Marketing Research 18(1), 39-50.

Gan, Y., Yang, M., Zhou, Y., \& Zhang, Y. (2007). The two-factor structure of future-oriented coping and its mediating role in student engagement. Personality and Individual Differences, 43(4), 851-863.

Geisser, S. (1974). A predictive approach to the random effect model. Biometrika, 61(1), 101-107

Gerrig R. J. \& Zimbardo P. G. (2001). Glossary of psychological terms. In: Gerrig RJ, Zimbardo PG, eds. Psychology and Life. 16th ed. Boston, MA: Allyn \& Bacon.

Gupta, S. K., Antony, J., Lacher, F., \& Douglas, J. (2018). Lean Six Sigma for reducing student dropouts in higher education-an exploratory study. Total Quality Management \& Business Excellence, 1-16.

Hair Jr, J. F., Sarstedt, M., Hopkins, L., \& Kuppelwieser, V. G. (2014). Partial least squares structural equation modelling (PLS-SEM). European Business Review. Vol. 26 No. 2, pp. 106-121

Hair, J. F., Risher, J. J., Sarstedt, M., \& Ringle, C. M. (2019). When to use and how to report the results of PLSSEM. European Business Review. Vol. 31 No 1, pp. 2-24.

Hair Jr, J. F., Hult, G. T. M., Ringle, C., \& Sarstedt, M. (2016). A primer on partial least squares structural equation modeling (PLS-SEM). Sage publications.

Hakanen, J. J., Bakker, A. B., \& Schaufeli, W. B. (2006). Burnout and work engagement among teachers. Journal of School Psychology, 43(6), 495-513.

Heffner, A. L., \& Antaramian, S. P. (2016). The role of life satisfaction in predicting student engagement and achievement. Journal of Happiness Studies, 17(4), 1681-1701.

Hobfoll, S. E. (2001). The influence of culture, community, and the nested self in the stress process: Advancing conservation of resources theory. Applied Psychology: An International Review, 50, 337-421.

Henseler, J., Ringle, C. M., \& Sarstedt, M. (2015). A new criterion for assessing discriminant validity in variancebased structural equation modeling. Journal of the Academy of Marketing Science, 43(1), 115-135.

Hudd, S. S., Dumlao, J., Erdmann-Sager, D., Murray, D., Phan, E., Soukas, N., \&Yokozuka, N. (2000) Stress at college: effects on health habits, health status and self-esteem. College Student Journal, 34, 1-9.

Kahu, E. R., \& Nelson, K. (2018). Student engagement in the educational interface: understanding the mechanisms of student success. Higher Education Research \& Development, 37(1), 58-71.

Kahn, W. 1990. Psychological conditions of personal engagement and disengagement at work. Academy of Management Journal, 33: 692-724.

Kahn, R. L., \& Juster, F. T. (2002). Well-Being: concepts and measures. Journal of Social Issues, 58(4), 627-644.

Kock, N., \& Lynn, G. (2012). Lateral collinearity and misleading results in variance-based SEM: An illustration and recommendations. Journal of the Association for Information Systems, 13(7).

Kugbey, N., Osei-Boadi, S., \& Atefoe, E. A. (2015). The Influence of Social Support on the Levels of Depression, Anxiety and Stress among Students in Ghana. Journal of Education and Practice, 6(25), 135-140.

Klem, A. M. \& Connel, J. P. (2004). Relationships matter: Linking teacher support to student engagement and achievement. Journal of School Health, 74(7), 262-273.

Kyndt, E., Dochy, F., Struyven, K., \& Cascallar, E. (2011). The perception of workload and task complexity and its influence on students' approaches to learning: A study in higher education. European Journal of Psychology of Education, 26(3), 393-415. 
Lassibille, G., \& Navarro Gómez, L. (2008). Why do higher education students drop out? Evidence from Spain. Education Economics, 16(1), 89-105.

Lazarus, R. S. (1966). Psychological stress and the coping process. New York: McGraw-Hill

Lee, J., Kim, E., \& Wachholtz, A. (2016). The effect of perceived stress on life satisfaction: The mediating effect of self-efficacy. Ch'ongsonyonhak yongu, 23(10), 29.

Leung, G. S., Yeung, K. C., \& Wong, D. F. (2010). Academic stressors and anxiety in children: The role of paternal support. Journal of Child and Family Studies, 19(1), 90-100.

Llorens, S., Schaufeli, W., Bakker, A., \& Salanova, M. (2007). Does a positive gain spiral of resources, efficacy beliefs and engagement exist? Computers in Human Behavior, 23(1), 825-841.

Løhre, A., Lydersen, S., \& Vatten, L. J. (2010). School wellbeing among children in grades 1-10. BMC Public Health, 10(1), 526.

Lyubomirsky, S., Sheldon, K. M., \& Schkade, D. (2005). Pursuing happiness: The architecture of sustainable change. Review of General Psychology, 9, 111-131.

Macaskill, A. (2012). Differentiating dispositional self-forgiveness from other forgiveness: Associations with mental health and life satisfaction. Journal of Social and Clinical Psychology, 31(1), 28-50.

Mat Roni, S. (2014). Introduction to SPSS. Edith Cowan University, SOAR Centre, Australia.

McAllister, Fiona (2005) Well-being: Concepts and Challenges. Discussion Paper. Edinburgh: The Sustainable Development Research Network.

McKnight, C. G., Huebner, E. S., \& Suldo, S. (2002). Relationships among stressful life events, temperament, problem behavior, and global life satisfaction in adolescents. Psychology in the Schools, 39(6), 677-687.

Manikandan, K. \& Neethu, A, T. (2018) Student Engagement in relation to Academic stress and Self-Efficacy. Guru Journal of Behavioural and Social Sciences Vol. 6 Issue, pp. 775-784

Mathew, M. J., Sudeep, C. B., Jain, J., \& Jain, V. (2017). Perceived sources of stress among postgraduate students of a dental college in Karnataka, India. Journal of Indian Association of Public Health Dentistry, 15(3), 230.

Mark, G. M., \& Smith, A. P. (2008). Stress models: A review and suggested new direction. Occupational Health Psychology, 3, 111-144.

Martin, A. J., Collie, R. J., \& Evans, P. (2016). Motivation and engagement in music: Theory, research, practice, and future directions. The Arts, Motivation and Engagement: How the Arts Makes a Difference; Fleming, J., Gibson, R., Anderson, M., Eds, 169-185.

Mérida-López, S., Extremera, N., \& Rey, L. (2017). Contributions of work-related stress and emotional intelligence to teacher engagement: additive and interactive effects. International Journal of Environmental Research and Public Health, 14(10), 1156.

Moksnes, U. K., Løhre, A., Lillefjell, M., Byrne, D. G., \& Haugan, G. (2016). The association between school stress, life satisfaction and depressive symptoms in adolescents: Life satisfaction as a potential mediator. Social Indicators Research, 125(1), 339-357.

Nelson, N. G., Dell' Oliver, C., Koch, C., \& Buckler, R. (2001). Stress, coping, and success among graduate students in clinical psychology. Psychological Reports, 88(3), 759-767.

Nielsen, I., Newman, A., Smyth, R., Hirst, G., \& Heilemann, B. (2017). The influence of instructor support, family support and psychological capital on the well-being of postgraduate students: a moderated mediation model. Studies in Higher Education, 42(11), 2099-2115.

Nitzl, C., Roldan, J. L., \& Cepeda, G. (2016). Mediation analysis in partial least squares path modeling. Industrial management $\&$ data systems.

Offstein, E. H., Larson, M. B., Mcneill, A. L., \& Mwale, H. M. (2004). Are we doing enough for today's graduate student? International Journal of Educational Management, Vol 18 No 7, 396-407.

Oswalt, S. B., \& Riddock, C. C. (2007). What to do about being overwhelmed: Graduate students, stress, and university services. College Student Affairs Journal, 27(1), 24-44.

Ouweneel, E., Le Blanc, P. M., \& Schaufeli, W. B. (2011). Flourishing students: A longitudinal study of positive emotions, personal resources, and study engagement. The Journal of Positive Psychology, 6(2), 142-153.

Ozbay, F., Johnson, D. C., Dimoulas, E., Morgan III, C. A., Charney, D., \& Southwick, S. (2007). Social support and resilience to stress: from neurobiology to clinical practice. Psychiatry (Edgmont), 4(5), 35. 
Park, S., Holloway, S. D., Arendtsz, A., Bempechat, J., \& Li, J. (2012). What makes students engaged in learning? A time-use study of within-and between-individual predictors of emotional engagement in low-performing high schools. Journal of youth and adolescence, 41(3), 390-401.

Pascoe, M. C., Hetrick, S. E., \& Parker, A. G. (2020). The impact of stress on students in secondary school and higher education. International Journal of Adolescence and Youth, 25(1), 104-112.

Passmore, J. (2019). Mindfulness in organisations (part 1): a critical literature review. Industrial and Commercial Training.

Podsakoff, P. M., MacKenzie, S. B., \& Podsakoff, N. P. (2012). Sources of method bias in social science research and recommendations on how to control it. Annual Review of Psychology, 63, 539-569.

Pyhältö, K., Toom, A., Stubb, J., \& Lonka, K. (2012). Challenges of becoming a scholar: A study of doctoral students' problems and well-being. International Scholarly Research Network Education, 7, 1-12.

Ramachandiran, M., \& Dhanapal, S. (2018). Academic Stress Among University Students: A Quantitative Study of Generation Y and Z's Perception. Pertanika Journal of Social Sciences \& Humanities, 26(3).

Raufelder, D., Kittler, F., Braun, S. R., Lätsch, A., Wilkinson, R. P., \& Hoferichter, F. (2014). The interplay of perceived stress, self-determination and school engagement in adolescence. School Psychology International, 35(4), 405-420.

Reeve, K. L., Shumaker, C. J., Yearwood, E. L., Crowell, N. A., \& Riley, J. B. (2013). Perceived stress and social support in undergraduate nursing students' educational experiences. Nurse education today, 33(4), 419-424.

Ribeiro, I. J., Pereira, R., Freire, I. V., de Oliveira, B. G., Casotti, C. A., \& Boery, E. N. (2018). Stress and quality of life among university students: A systematic literature review. Health Professions Education, 4(2), 70 77.

Rickwood, D., Telford, N., O'Sullivan, S., Crisp, D., \& Magyar, R. (2016). National tertiary student wellbeing survey 2016.

Roddenberry, A. C. (2007). Locus of Control and Self-efficacy: Potential mediators of stress, illness, and utilisation of health services in college students (Unpublished doctoral dissertation). Orlando, Florida: University of Central Florida.

Roslan, S., Ahmad, N., Nabilla, N., \& Ghiami, Z. (2017). Psychological well-being among postgraduate students. Acta Medica Bulgarica, 44(1), 35-41.

Salanova, M., Schaufeli, W. B., Xanthopoulou, D., \& Bakker, A. B. (2010). The gain spiral of resources and work engagement: Sustaining a positive work-life. Work engagement: A handbook of essential theory and research, 118-131.

Salmela-Aro, K., \& Upadyaya, K. (2014). School burnout and engagement in the context of demands-resources model. British journal of educational psychology, 84(1), 137-151.

Seligman, M. E. P., \& Csikszentmihalyi, M. (2000). Positive psychology [Special issue]. American Psychologist, 55(1), 5-14.

Schaufeli, W. B., Martinez, I. M., Pinto, A. M., Salanova, M., \& Bakker, A. B. (2002). Burnout and engagement in university students: A cross-national study. Journal of Cross-Cultural Psychology, 33(5), 464-481.

Schaufeli, W. B., \& Taris, T. W. (2014). A critical review of the job demands-resources model: Implications for improving work and health. In Bridging occupational, organisational and public health (pp. 43-68). Springer, Dordrecht.

Schaufeli, W. B. (2017). Applying the job demands-resources model. Organizational Dynamics, 2(46), 120-132.

Schwarzer, R., Knoll, N., \& Rieckmann, N. (2004). Social support. In A. Kaptein, \& J. Weinman (Eds), Health Psychology (pp. 158-182). Oxford, UK: Blackwell.

Sheu, H. B., Liu, Y., \& Li, Y. (2017). Well-being of college students in China: Testing a modified social cognitive model. Journal of Career Assessment, 25(1), 144-158.

Skinner, E. A., \& Pitzer, J. R. (2012). Developmental dynamics of student engagement, coping, and everyday resilience. In Handbook of research on student engagement (pp. 21-44). Springer, Boston, MA.

Sinclair, M. F., Christenson, S. L., Lehr, C. A., \& Anderson, A. R. (2003). Facilitating student engagement: Lessons learned from Check \& Connect longitudinal studies. The California School Psychologist, 8(1), 29-41.

Smalley, S. L. \& Winston, D. (2010). Fully present: The science, art, and practice of mindfulness. United States of America: De Capo Press.

Sorias O., (1988a). Sosyal desteklerin ruhsal sa $\div 10 \tilde{O} \div$ Õ koruyucu etkisinin depresyonlu ve sa $\div 10 ̃$ lõ kontrollerde araútÕrÕlmasÕ. Ege Üniversitesi TÕp Fakültesi Dergisi, 27, 3, 1033-1039. 
Sorias O., (1988b). Yaúam stresine karúÕ koruyucu olarak sosyal destekler, Edebiyat Fakültesi YayÕnlarÕ, Seminer Psikoloji (Özel sayÕ), 805-811.

Stallman, H. M. (2010). Psychological distress in university students: A comparison with general population data. Australian Psychologist, 45(4), 249-257.

Stallman, H. M., Ohan, J. L., \& Chiera, B. (2018). The role of social support, being present and self-kindness in university student well-being. British Journal of Guidance \& Counselling, 46(4), 365-374.

Strati, A. D., Schmidt, J. A., \& Maier, K. S. (2017). Perceived challenge, teacher support, and teacher obstruction as predictors of student engagement. Journal of Educational Psychology, 109(1), 131.

Streeter, C. L., \& Franklin, C. (1992). Defining and measuring social support: Guidelines for social work practitioners. Research on Social Work Practice, 2(1), 81-98.

Stone, M. (1974). Cross-validatory choice and assessment of statistical predictions. Journal of the Royal Statistical Society: Series B (Methodological), 36(2), 111-133.

Styger, A., Van Vuuren, G. W., \& Heymans, A. (2015). Case study of postgraduate student dropout rate at South African universities, International Business \& Economics Research Journal - January/February 14(1), 114.

Suldo, S. M., \& Huebner, E. S. (2004). Does life satisfaction moderate the effects of stressful life events on psychopathological behavior during adolescence? School Psychology Quarterly, 19(2), 93.

Suldo, S. M., \& Huebner, E. S. (2006). Is extremely high life satisfaction during adolescence advantageous? Social Indicators Research, 78(2), 179-203.

Tian, L., Zhao, J., \& Huebner, E. S. (2015). School-related social support and subjective well-being in school among adolescents: The role of self-system factors. Journal of Adolescence, 45, 138-148.

Tinto, V. (2010). From theory to action: Exploring the institutional conditions for student retention. In Higher education: Handbook of theory and research (pp. 51-89). Springer, Dordrecht.

Tinto, V., \& Engstrom, C. (2008). Access without support is not opportunity. Inside Higher Ed, 9, 8-18.

Tov, W. (2018). Well-being concepts and components. In E. Diener, S. Oishi, \& L. Tay (Eds.), Handbook of wellbeing. Salt Lake City, UT: DEF Publishers

Travers, P., \& Richardson, S. (1993). In defence of complex equality. In Theory and Practice in Australian Social Policy: Rethinking the Fundamentals, Proceedings of the National Social Policy Conference.

Trowler, V. (2010). Student engagement literature review. The Higher Education Academy, 11(1), 1-15.

Trowler, V. \& Trowler, P. (2010). Student engagement evidence summary, York, UK: Higher Education Academy.

Waldron, S. (2010), Measuring Subjective Wellbeing in the UK, ONS Report 2010

Wigfield, A., Eccles, J. S., Schiefele, U., Roeser, R., \& Davis-Kean, P. (2006). Development of achievement motivation. In W. Damon (Series Ed.) \& N. Eisenberg (Vol. Ed.), Handbook of child psychology, 6th Ed. Vol. 3. Social, emotional, and personality development (pp. 933-1002). New York: John Wiley.

Valle, A., Regueiro, B., Núñez, J. C., Rodríguez, S., Piñeiro, I., \& Rosário, P. (2016). Academic goals, student homework engagement, and academic achievement in elementary school. Frontiers in Psychology, 7, 463.

Veiga, F. H., Galvão, D., Almeida, A., Carvalho, C., Janeiro, I., Nogueira, J., ... Caldeira, S. (2012). Student's engagement in school: A literature review. In Proceedings of ICERI2012 conference, 19th-21st November (pp. 1336-1344).

Wang, M. T., \& Degol, J. (2014). Staying engaged: Knowledge and research needs in student engagement. Child Development Perspectives, 8(3), 137-143.

Wang, M. T., \& Eccles, J. S. (2012). Social support matters: Longitudinal effects of social support on three dimensions of school engagement from middle to high school. Child development, 83(3), 877-895.

Wang, M. T., \& Eccles, J. S. (2012). Adolescent behavioral, emotional, and cognitive engagement trajectories in school and their differential relations to educational success. Journal of Research on Adolescence, 22(1), 31-39.

White, S.C. (2008). But What is Wellbeing? A Framework for Analysis in Social and Development Policy and Practice. WeD Working Paper No. 43. Well-being in Developing Countries ESRC Research Group, University of Bath, Bath, $18 \mathrm{pp}$

Woosley, S. A., \& Miller, A. L. (2009). Integration and institutional commitment as predictors of college student transition: Are third-week indicators significant? College Student Journal, 43(4), 1260-1272.

Woosley, S. A., \& Shepler, D. K. (2011). Understanding the early integration experiences of first-generation college students. College Student Journal, 45(4), 700-715.

Xerri, M. J., Radford, K., \& Shacklock, K. (2018). Student engagement in academic activities: a social support perspective. Higher education, 75(4), 589-605. 
Yang, C., Xia, M., Han, M., \& Liang, Y. (2018). Social support and resilience as mediators between stress and life satisfaction among people with substance use disorder in China. Frontiers in Psychiatry, 9, 436.

Yusoff, M. S. B., \& Rahim, A. F. A. (2010). Prevalence and sources of stress among postgraduate medical trainees: initial findings. Case Reports Review Article, 11(2), 180-189.

Vargas, J. D. P., Ríos, M. F., Aravena, M. B., Vielma, R. G. R., Mebarak, M., Curcio, M. J. Z., ... \& Guerra, M. (2018). Relationships Between Work Design, Engagement, and Life satisfaction. Psicología Desde el Caribe: festival del Programa de Piscología de la Universidad del Norte, 35, 98-108.

Zegeye, A., Mossie, A., Gebrie, A., \& Markos, Y. (2018). Stress among Postgraduate Students and Its Association with Substance Use. J Psychiatry, 21, 448.

Zhao, C. M., \& Kuh, G. D. (2004). Adding value: Learning communities and student engagement. Research in Higher Education, 45(2), 115-138.

Zhao, C. M., Kuh, G. D., \& Carini, R. M. (2005). A comparison of international student and American student engagement in effective educational practices. The Journal of Higher Education, 76(2), 209-231.

Zhao, X., Lynch Jr, J. G., \& Chen, Q. (2010). Reconsidering Baron and Kenny: Myths and truths about mediation analysis. Journal of consumer research, 37(2), 197-206.

Zepke, N., \& Leach, L. (2010). Improving student engagement: Ten proposals for action. Active Learning in Higher Education, 11(3), 167-177. 